\title{
Teoría y praxis de los derechos ambientales en Argentina ${ }^{1}$ Theory and praxis of environmental rights in Argentina
}

\section{Ricardo A. Gutiérrez}

Ricardo A. Gutiérrez es Profesor Titular Regular, Escuela de Política y Gobierno, de la Universidad Nacional de San Martín e Investigador Adjunto del Consejo Nacional de Investigaciones Científicas y Técnicas, Argentina.

E-mail: newgutix@gmail.com

\section{resumen}

Nuevos derechos ambientales fueron introducidos en Argentina con la reforma constitucional de 1994. El reconocimiento constitucional de los derechos ambientales es un paso fundamental en el avance de la justicia y la ciudadanía ambientales. Pero no es suficiente. Los principios constitucionales deben traducirse en legislación y la legislación debe ser efectivamente aplicada. Mientras algunos autores se centran en los procedimientos administrativos y judiciales y en la participación institucionalizada en el proceso de toma de decisiones, este trabajo busca construir un enfoque emergente que ayude a analizar la aplicación de los derechos ambientales en Argentina desde una perspectiva más amplia que vaya más allá de los procedimientos y la participación institucionalizada y que también tome en cuenta el rol de la acción contenciosa o contienda ambiental. Argumento que tres modos de contienda ambiental convergen en la actualización de los derechos ambientales: el litigio judicial, la protesta social y la controversia experta. A la luz del desarrollo reciente de las movilizaciones y las políticas ambientales en Argentina, este trabajo discute cómo esos modos se manifiestan, se combinan entre sí y se conectan con la participación institucionalizada.

\section{summary}

New environmental rights were introduced in Argentina with the 1994 amendments to the 1853 national constitution. The constitutional recognition of environmental rights is a fundamental step in the advancement of environmental justice and citizenship. But it is not enough. Constitutional principles must be translated into enabling legislation and legislation must be effectively applied and enforced. While some authors focus on administrative and judicial enforcement procedures and institutionalized participation in decision-making, this work aims to build up an emergent framework that helps analyze the enforcement of environmental rights in Argentina from a broader perspective that goes beyond procedures and institutionalized participation and also takes into account the role of environmental contention. I argue that three modes of environmental contention combine in the actualization of environmental rights: judicial litigation, social protest, and expert controversy. In the light of the recent development of environmental mobilization and policies in Argentina, this article discusses how these modes manifest themselves and combine, and also how they connect to institutionalized participation.

\section{palabras clave}

derechos ambientales / participación / ambientalismo / políticas ambientales

\section{keywords}

environmental rights / participation environmentalism / environmental policies 


\section{Introducción}

El reconocimiento constitucional de los derechos ambientales es un paso fundamental en el avance hacia la justicia ambiental. Como en muchos otros países, a mediados de los años 1990 en Argentina tuvo lugar un proceso de reforma constitucional que dio nacimiento, entre otras cosas, al derecho a un ambiente sano y a una serie de derechos vinculados. Pero los principios constitucionales tienen que traducirse en legislación y la legislación tiene que ser implementada y respetada. Mientras algunos autores se centran en los procedimientos administrativos y judiciales y en la participación institucionalizada como mecanismos para aplicar y hacer cumplir la ley (Hajer, 1995; Azuela, 2006; Hiskes, 2009), este trabajo busca construir un marco que permita analizar la actualización de los derechos ambientales en Argentina desde una perspectiva política más amplia, la cual vaya más allá de la participación institucionalizada y los procedimientos formales y también tome en cuenta el rol de la protesta social y de las controversias expertas.

Los derechos ambientales son definidos, apropiados y exigidos por actores sociales y estatales a través de distintas formas de acción. La participación social (ampliamente entendida) ayuda a posicionar las cuestiones ambientales en la agenda pública (Downs, 1972; Harrison, 1996) a la vez que funciona como un mecanismo democrático para el control social de las decisiones de las elites económicas y políticas (Peruzzotti y Smulovitz, 2002; Merlinsky, 2009). También actualiza y resignifica los derechos ambientales incidiendo tanto en la definición pública (Offe, 1992; Hajer, 1995) como en la definición jurídico-legal de esos derechos (Azuela, 2006).

Abrevando en una larga tradición de la ciencia política que puede remontarse hasta la defensa que Maquiavelo hace del tumulto como motor de la república romana, aquí se argumenta que distintos modos de acción contenciosa son tan importantes como los mecanismos de participación institucionalizada (vg. consejos, comités, audiencias públicas) en la apropiación y puesta en vigencia de los derechos ambientales. Fundado en la casuística argentina, este trabajo propone un enfoque que, sin negarla, va más allá de la participación institucionalizada en la formulación y ejecución de políticas públicas a la vez que busca ampliar el concepto mismo de acción contenciosa.

Sin ignorar, entonces, la relevancia de los derechos propiamente procedimentales y las formas de participación institucionalizada, se argumenta que tres modos de acción contenciosa o contienda ambiental ${ }^{2}$ convergen en la actualización de los derechos ambientales en Argentina: el litigio judicial, la protesta social y la controversia experta. Estos modos se manifiestan y se combinan de diferentes maneras en los casos específicos, y también pueden combinarse con otros modos de participación no contenciosa.

En lo que sigue, primero se discutirá la naturaleza de los derechos ambientales y la centralidad que tiene la participación institucionalizada desde la perspectiva del llamado enfoque emergente. A continuación, se definirán las particularidades que asumen los derechos ambientales en Argentina. Luego se definirán e ilustrarán los modos de contienda ambiental predominantes en Argentina, previa discusión de 
cómo se entiende aquí la acción contenciosa. Finalmente, en las consideraciones finales se propondrán algunas líneas para avanzar en un enfoque de la praxis de los derechos ambientales que preste atención tanto a la contienda ambiental como a los modos de participación institucionalizada.

\section{¿En qué consisten los derechos ambientales?}

En una primera y simple versión, los derechos ambientales pueden ser definidos como los derechos humanos al aire, el agua y el suelo limpios, no sólo para los ciudadanos actuales sino también para los ciudadanos futuros (Hiskes, 2009). Así definidos, los derechos ambientales poseen tres características importantes.

Primero, los derechos ambientales son derechos colectivos. El fundamental "derecho a la vida" presupone el derecho más básico a disponer de aire, agua y suelo limpios, y estos bienes ambientales son indefectiblemente bienes colectivos que no respetan constreñimientos de espacio o tiempo (Hiskes, 2009). Esta característica de los derechos ambientales tiene dos implicancias fundamentales: 1) las generaciones presentes son responsables por los bienes ambientales de las generaciones futuras y; 2) las acciones legales del caso pueden ser perseguidas no sólo por aquellos directamente afectados por la contaminación o el riesgo ambientales sino también por organizaciones que, de un modo u otro, representen los intereses difusos de las siguientes generaciones (ver infra sobre "derechos colectivos" y "acción colectiva" en Argentina).

Segundo, los derechos ambientales son materia de justicia. ¿Por qué? Porque tanto la contaminación como las políticas ambientales tienen efectos distributivos (Harrison, 1996; Hiskes, 2009). Respecto de los efectos distributivos de la contaminación, ha sido ampliamente señalado que no todos los grupos sociales están igualmente expuestos a los riesgos ambientales (vg. Acselrad, 2006).

Pero los derechos ambientales también implican efectos distributivos en lo que respecta a las políticas públicas generadas para enfrentar la contaminación dado que "el costo [de esas políticas] recaerá más fuertemente en algunas personas que en otras y el bien ambiental beneficiará más a unos que a otros"3 (Hiskes, 2009: 20; corchetes míos).

Tercero, los derechos ambientales incluyen un número de derechos procedimentales a través de los cuales ciudadanos y organizaciones sociales pueden asegurar o reclamar la protección del aire, el agua y el suelo limpios (Hajer, 1995; Acuña, 2003; Azuela, 2006; Hiskes, 2009). Es por esta razón que es más apropiado hablar de derechos ambientales, en plural. Así, por derechos ambientales aquí entenderemos el derecho a gozar de agua, aire y suelo limpios más el conjunto de derechos procedimentales establecidos para su defensa.

Para Hiskes (2009), los derechos procedimentales han sido definidos del modo más abarcador por el Informe Ksentini de 1994, luego incorporado en la Convención de Aarhus de 19984; a saber: 1) derecho a la información relativa al ambiente, 2) derecho a sostener y expresar opiniones y a diseminar ideas e información relativas al ambiente, 3 ) derecho a la educación en materia de derechos humanos y ambientales, 4) derecho a la participación activa, libre y significativa en el proceso 
de toma y ejecución de decisiones, 5) derecho a asociarse libre y pacíficamente con otros para fines de protección del ambiente o de los derechos de las personas afectadas por daños ambientales y 6) derecho a la reparación efectiva por daños ambientales a través de procedimientos administrativos o judiciales.

De modo similar, el experto de la CEPAL, Guillermo Acuña, se refiere al Principio 10 de la Declaración de Río de Janeiro de 1992 como el "Principio de Acceso" (acceso a la información, la participación institucionalizada y a la reparación administrativa y legal), el cual sintetiza bajo la expresión "derecho a saber, participar y demandar" (Acuña, 2003).

¿Pero de dónde vienen los derechos ambientales? Para responder esta pregunta, puede recurrirse al concepto de "juridificación" definido por Azuela (2006) en base a la teoría de los campos de Bourdieu. Por juridificación, Azuela (2006:1314) entiende

"[el] proceso social por el cual las expectativas que se forman en el 'campo ambiental' (o sea, las expectativas acerca de qué debemos hacer sobre la cuestión ambiental) se convierten en 'enunciados jurídicos' para ser incorporados al horizonte cultural de los actores que participan en dicho campo".

Así, los derechos ambientales (tal como se expresan en el sistema legal estatal) provienen de la juridificación de la cuestión ambiental que se produce en el cruce de dos campos: el "campo ambiental" (cuyo "núcleo duro" lo constituyen las organizaciones y movimientos ambientales) y el "campo del derecho" (dominado por abogados). Es en este cruce que las expectativas normativas de la sociedad sobre el ambiente se transforman en enunciados legales que, a su vez, vuelven al campo ambiental bajo la forma de derechos humanos.

El proceso de juridificación nos remite al enfoque emergente de los problemas y derechos ambientales propuesto tanto por Hannigan (2006) como por Hiskes (2009). El concepto de emergencia "denota proceso, flujo, adaptación y aprendizaje" y "refiere al hecho de que estas ideas, creencias y normas están en proceso de reformulación permanente" (Hannigan, 2006: 144).

Desde una perspectiva emergente, los derechos ambientales son concebidos como derechos humanos y "la transición de los derechos 'naturales' a los derechos 'humanos' indica que nuestra visión de los derechos está abierta al desarrollo y el crecimiento" (Hiskes, 2009). Partiendo de esta visión "abierta”, Hiskes argumenta que los derechos ambientales emergen y se definen dentro de una determinada comunidad nacional, centrándose en la importancia del estatus constitucional de los derechos ambientales. Sostiene que, en vez de recurrir a regímenes o acuerdos internacionales, el mejor camino para arribar a la protección real de los derechos ambientales consiste en descansar en la voluntad política presente dentro de cada comunidad política individual, la que se manifiesta en la constitución nacional. La constitución es de gran importancia, no sólo porque encarna el reconocimiento de la relevancia que una sociedad otorga a la protección ambiental y consagra los derechos humanos como derechos inalienables, sino también porque expresa el sentido de conexión entre ciudadanos a través de las generaciones que es intrínseco a los derechos ambientales: 
"Como elementos constitucionales, los derechos consagrados presentan un cuadro intergeneracional y relacional único de la comunidad a través del tiempo, esto es, un conjunto de personas que comparten una serie de valores y una identidad que los hace reconocibles como co-ciudadanos sin importar cuán separados estén por el paso del tiempo... las personas viven y mueren, pero las naciones continúan y los ciudadanos se reconocen unos a otros como co-nacionales en el curso de los siglos. ¿Por qué? Porque comparten las mismas creencias, los mismos valores y los mismos principios consagrados (de manera escrita o no) en su constitución compartida" (Hiskes, 2009: 127-128).

Pero la consagración constitucional de los derechos ambientales no es suficiente. Los derechos ambientales tienen que ser implementados y respetados. Una vez consagrados constitucionalmente, los derechos ambientales (generales como son) tienen que traducirse en una legislación más detallada y efectiva. Y una vez que el proceso legislativo llega a su (provisorio) fin, es tiempo para la implementación y el cumplimiento de la legislación ambiental (supuestamente) fundamentada en los derechos constitucionales. Es en esta etapa, desde el trámite legislativo en adelante, cuando los derechos procedimentales mencionados anteriormente resultan más cruciales.

\section{Derechos ambientales y participación institucionalizada}

Desde un enfoque emergente, el goce de los derechos ambientales depende, como ya se adelantó, de procedimientos administrativos y judiciales y la implementación de estos últimos está estrechamente vinculada con el "derecho a saber, participar y demandar". Es sólo en este punto que el sentido social (y no meramente "legal") de los derechos constitucionales debe buscarse. Estamos de vuelta, en términos de Azuela (2006: 26), en el campo ambiental,

"donde se elaboran, procesan y seleccionan las respuestas sociales a la crisis ambiental, es allí donde hay que buscar el 'sentido' de las normas ambientales: no sólo en la definición constitucional-legislativa sino también en los procedimientos de aplicación".

Es por ello que la naturaleza emergente de los derechos ambientales (como la de todos los derechos) refiere no solamente a sus orígenes comunitarios sino también al hecho de que esos derechos están en un proceso de re-formulación permanente en virtud de los modos en que los ciudadanos y grupos sociales se apropian de, y disputan, esos derechos. Desde la perspectiva emergente hasta aquí reconstruida, esos modos son entendidos centralmente en términos de participación institucionalizada, considerada ésta un elemento clave para la actualización de los derechos ambientales constitucionales.

Por participación institucionalizada puede entenderse los modos de participación social que surgen de la transformación de las características voluntarias de la sociedad civil en formas de organización política permanente basadas en la interacción con actores estatales y partidos políticos y en la efectividad de las instituciones creadas para la participación en la formulación y ejecución de políticas públicas (Avritzer, 2009). Dos elementos son centrales en esta concepción de la 
participación: instituciones y proceso de toma de decisiones. Mediante el diseño de instituciones formales específicas, "las prácticas de la sociedad civil se vuelven institucionalizadas como formas permanentes de interacción con el estado" (Avritzer, 2009: 9). A su vez, esas instituciones son creadas con el objetivo específico de fortalecer "la participación de los actores sociales en la deliberación y la toma de decisiones" (Avritzer, 2002: 137). Es decir, las instituciones en cuestión están menos orientadas a la expresión de demandas o la presentación de reclamos que a la solución administrativa de problemas públicos.

La importancia de la participación institucionalizada en la toma de decisiones es resaltada por Hiskes (2009: 133-34), quien argumenta que la instauración de la justicia ambiental depende tanto del constitucionalismo como de la democracia participativa. El acceso efectivo a la información y la oportunidad de participar en los procesos de toma de decisión a través de procedimientos administrativos son cruciales para la ciudadanía ambiental. Más aún, la participación institucionalizada en la toma de decisiones previene la determinación no democrática de los tribunales: "sólo ante la ausencia de la participación activa de los ciudadanos... pueden los tribunales intervenir y tomar una (admitidamente no democrática) determinación" (2009: 137). Es por ello que Hiskes (2009: 139) sostiene que existe una conexión intrínseca entre los derechos humanos ambientales sustantivos y los derechos democráticos procedimentales para la toma de decisiones ambientales.

De modo similar, Hajer (1995: 280-81) propone una alternativa "reflexiva" a la modernización ecológica (ver infra) que descansaría en

"nuevos arreglos institucionales [i.e. la consulta social y la ley discursiva] en los cuales diferentes discursos (y preocupaciones) pueden ser significativa y productivamente vinculados... en una manera que estimule la creación de una visión compartida del futuro" (corchetes míos).

Hajer (1995: 286) argumenta, en línea con Hiskes, que la participación tempra$n a$ es más efectiva que el litigio tardío y explica que

"muchas de las frustraciones de los gobiernos y de las empresas con la participación o los derechos legales provienen del hecho de que las prácticas institucionales existentes sólo permiten comentarios u objeciones sobre planes que ya están en su forma final".

Sin negar la relevancia de los derechos propiamente procedimentales y las formas de participación institucionalizada, aquí se argumenta que las "respuestas sociales a la crisis ambiental" no pueden ser acabadamente comprehendidas dentro de los términos del "derecho a saber, participar y demandar" tal cual como lo hemos visto hasta ahora. No es la relevancia política o normativa de aquellos derechos lo que aquí se pone en duda sino su validez analítica como instrumentos a través de los cuales organizaciones sociales y ciudadanos de a pie se apropian de, y redefinen, el derecho al aire, el agua y el suelo limpios. Como veremos a la luz del caso argentino, la movilización de aquellos que forman el campo ambiental va más allá de los procedimientos administrativos implícitos en una visión restringida del "derecho a saber, participar y demandar". 
La participación institucionalizada en la formación de políticas ambientales es, en Argentina, bastante imperceptible, mientras que la participación de ciudadanos y organizaciones en protestas sociales y litigios judiciales ha sido muy efectiva en colocar las cuestiones ambientales en la primera plana de la agenda pública, en amplificar la importancia de los derechos ambientales introducidos con la reforma de 1994 y, a veces, incluso en cambiar o dirigir el curso de decisiones estatales. Es por eso que aquí se propone un enfoque ampliado, centrado en la incidencia de la acción contenciosa ambiental. Este enfoque presta más atención al derecho procedimental a demandar (tal como se expresa en el litigio judicial) junto con otros modos de acción contenciosa (la protesta social y la controversia experta) que son claves para la aplicación de los derechos ambientales y que no pueden ser apropiadamente aprehendidos desde un enfoque meramente procedimentalista. Pero antes, repasemos brevemente en qué consisten los derechos ambientales consagrados por la reforma constitucional de 1994.

\section{Derechos ambientales en Argentina}

Con la reforma de 1994, los derechos ambientales fueron incorporados al conjunto de derechos y garantías inalienables consagrados en la constitución nacional de 1853. El nuevo Artículo 41 establece lo siguiente:

"Todos los habitantes gozan del derecho a un ambiente sano, equilibrado, apto para el desarrollo humano y para que las actividades productivas satisfagan las necesidades presentes sin comprometer las de las generaciones futuras; y tienen el deber de preservarlo. El daño ambiental generará prioritariamente la obligación de recomponer, según lo establezca la ley.

Las autoridades proveerán a la protección de este derecho, a la utilización racional de los recursos naturales, a la preservación del patrimonio natural y cultural y de la diversidad biológica, y a la información y educación ambientales.

Corresponde a la Nación dictar las normas que contengan los presupuestos mínimos de protección, y a las provincias, las necesidades para complementarlas, sin que ellas alteren las jurisdicciones locales.

Se prohíbe el ingreso al territorio nacional de residuos actual o potencialmente, y de los radioactivos".

El Artículo 41 se complementa con los Artículos 43 (recurso de amparo, derechos colectivos y acción colectiva), 75 inciso 19 (desarrollo humano), 75 inciso 22 (tratados internacionales), 86 (Defensor del Pueblo de la Nación) y 124 (dominio provincial sobre los recursos naturales, y también con la Ley General del Ambiente de 2002 (Ley 25.675/02). Todas juntas, estas normas definen el derecho sustantivo a un ambiente sano para las generaciones presentes y futuras (i.e. derecho al agua, aire y suelo limpios) como un derecho colectivo y lo complementan con un número de importantes derechos y principios procedimentales:

- Derecho a la información y la educación ambientales.

- Derecho a la reparación de acuerdo a procedimientos legales establecidos.

- Recurso de amparo para la protección de derechos y garantías constitucionales. - Acción colectiva para demandar la protección de derechos colectivos (no sólo los 
afectados directamente sino también el Defensor del Pueblo y asociaciones civiles que representan intereses difusos pueden presentar una demanda judicial).

- Principio de "federalismo concertado" para la distribución de competencias legislativas y ejecutivas entre el gobierno nacional y los gobiernos provinciales (el Estado nacional debe establecer los presupuestos mínimos de protección ambiental y las provincias deben aprobar y aplicar la legislación complementaria).

De acuerdo con el abogado constitucionalista y ambientalista Daniel Sabsay (2003), la constitución reformada enmarca los derechos ambientales dentro de un enfoque de desarrollo sostenible toda vez que establece que el derecho al ambiente sano debe ser "apto para el desarrollo humano y para que las actividades productivas satisfagan las necesidades presentes sin comprometer las de las generaciones futuras" (Artículo 41). De ser así, los derechos ambientales argentinos, tal como son constitucionalmente consagrados, están fundados en lo que Hajer define como el enfoque de la modernización ecológica, cuyo presupuesto fundamental es que "el crecimiento económico y la solución de los problemas ecológicos pueden, en principio, ser reconciliados" (1995: 25-26).

Pero, como lo muestran muchos estudios (cf. vg. Alimonda, 2003, 2006; Alvarado Merino et al., 2008), el significado social del desarrollo sostenible no es fijo ni unívoco. Depende de la disputa entre aquellos involucrados en una contienda ambiental concreta, razón por la cual el contenido y los límites del concepto son inestables. De modo similar, aquí se asume que los derechos ambientales constitucionales son un punto de partida para la definición y el enmarcamiento de los problemas ambientales, constituyendo un instrumento muy importante para los contendientes en un caso determinado. Pese a expresar una visión poco optimista de la legislación ambiental, así lo reconocía Javier Rodríguez Pardo (pionero de la protesta ambiental contra la minería a cielo abierto en Argentina) respecto de la discusión legislativa de los presupuestos mínimos para la protección de glaciares:

"Algunos pensamos que la mejor ley de protección de glaciares, cualquiera que sea, no resuelve el impacto nocivo de la minería. Por sí sola, esta norma legal (como cualquier otra) está desamparada y bien puede ser utilizada con el argumento de que 'se hace minería conforme a la legislación vigente', refrendada por la provincia, generalmente asociada a intereses mineros. Sin embargo, es una herramienta vital a utilizar por los movimientos sociales y en debates públicos. Nos permitirá ejercer un observatorio permanente que atienda a su cumplimiento, y nos obliga a exigir el acatamiento de la evaluación del impacto ambiental" (Navarra, 2010: 40; el resaltado es propio).

Pero ¿por qué los ambientalistas consideran a la legislación una "herramienta vital" cuando, a su vez, tienen tan baja estima de la labor legislativa? Porque la discusión legislativa remite directamente a los derechos ambientales consagrados en la constitución. Cualquiera que sea la relación entre desarrollo sostenible y modernización ecológica, el derecho a un ambiente sano es consagrado en la constitución como un derecho humano inalienable y como tal puede volverse un recurso invaluable en manos de las organizaciones ambientales que, por ejemplo, se oponen, como Rodríguez Pardo, a la minería a cielo abierto. 


\section{Modos de contienda ambiental en Argentina}

Como se adelantó en la introducción, este trabajo se propone no sólo ir más allá de la participación institucionalizada sino también ampliar el concepto mismo de acción contenciosa. Propone, de ese modo, un enfoque que, sin negar la relevancia de la primera, amplíe el espectro de la contienda ambiental más allá de la protesta para incluir otros dos modos de acción contenciosa: el litigio judicial y la controversia experta. Para ello, podemos partir de una definición básica según la cual la acción contenciosa consiste en la "acción común de un grupo que directamente afecta los intereses de otro grupo en acción" (Tilly, 1986: 381-82). El primer elemento que surge en esta definición es la confrontación o contraposición de intereses, es decir, la noción de que un grupo se moviliza en demanda de intereses cuya satisfacción afectaría los intereses de otro grupo. Tilly lo pone más claramente en uno de sus últimos textos cuando aclara que los movimientos sociales son contenciosos porque "plantean reivindicaciones colectivas que, de ser aceptadas, chocarían con los intereses de otras personas" (Tilly y Wood, 2010: 21). Por su parte, McAdam, Tarrow y Tilly (2001: 5) refuerzan la idea de que la política contenciosa es una forma adversarial de expresar reivindicaciones en la cual "las demandas, de ser concretadas, afectarían los intereses de al menos una de las partes involucradas".

En resumen, dos elementos son centrales en la definición de acción contenciosa: 1) expresión de demandas o reivindicaciones y 2) confrontación de grupos con intereses contrapuestos. Dado que este concepto ha sido desarrollado mayormente dentro de los estudios sobre movimientos sociales, no es de extrañar que la acción contenciosa tienda a ser identificada con formas "disruptivas" o "desafiantes" de acción. Eso se aprecia en la definición de acción contenciosa de Tarrow (2011: 7):

"La acción se vuelve contenciosa cuando es usada por gente que carece de acceso regular a las instituciones representativas, que actúa en nombre de reclamos nuevos o no aceptados y que se comporta en modos que fundamentalmente desafian a otros o a las autoridades" (mi resaltado).

Esos modos desafiantes de comportamiento a los que alude Tarrow remiten a la noción de protesta social. ¿Qué es lo que agrega la noción de protesta respecto de la definición básica de acción contenciosa? Una particular forma de acción: formas no convencionales, no institucionalizadas y disruptivas de acción. Tarrow define a la protesta como "una acción directa y disruptiva en nombre de intereses colectivos, en la cual los reclamos son hechos contra otro grupo, las elites o las autoridades" (1989: 359, citado en Tilly, 2008: 24). Dellaporta y Diani (2006: 191), por su parte, definen a la protesta como aquella "acción no rutinizada en la cual canales indirectos de influencia se abren a través de la actividad de actores colectivos". Esos canales indirectos de influencia consisten en las formas disruptivas o desafiantes de acción a las que refiere Tarrow (vg. boicots, barricadas, peticiones, movilizaciones) y operan en base a una triple lógica: mostrar el mayor número posible, infringir algún "daño" y "dar testimonio", principalmente ante los medios de comunicación (Della Porta y Diani, 2006: 169-78). 
Sin embargo, Tilly y sus colegas (McAdam, Tarrow y Tilly, 2001; Tilly y Wood, 2010) aclaran en varios textos (aunque no lo elaboran en profundidad) que la acción "disruptiva" de los movimientos sociales no es la única forma de contienda posible. Precisamente, lo que distingue a la acción del movimiento social de otras formas de contienda es la acción disruptiva que está contenida en el concepto de protesta. De ahí que varios autores, identifiquen a la protesta y a los movimientos sociales como formas "no convencionales" de expresión de demandas (vg. Offe, 1992; Dalton, Recchia y Rohrschneider, 2003; Della Porta y Diani, 2006). Pero los movimientos sociales, al igual que la protesta, son una forma de acción contenciosa. Si, como advierte Tarrow (2011), la protesta no alcanza para definir al movimiento social, éste no agota las formas de acción contenciosa.

En Dynamics of Contention, luego de definir la acción contenciosa en términos de expresión de demandas y confrontación de grupos con intereses contrapuestos, McAdam, Tarrow y Tilly (2001: 5-7) distinguen entre "contienda contenida" (cuando actores previamente establecidos emplean medios bien establecidos de reclamo) y "contienda transgresiva" (cuando alguna de las partes es un actor "nuevo" y/o utiliza formas "innovativas" de acción). Esta distinción supone que no hay nada en la definición general de acción contenciosa que haga de la protesta un elemento inherente al concepto; la protesta sería propia de la contienda transgresiva. Si bien aclaran que su libro sólo está dedicado a la contienda transgresiva, los propios autores advierten la importancia de prestar más atención a la contienda contenida y a su interacción con la contienda transgresiva (2001: 305).

En ese mismo sentido, en el cierre de la última edición de Power in Movement, Tarrow (2011) advierte sobre la importancia de prestar más atención a la contienda contenida y la "multiplicidad de formas híbridas de interacción que aúnan la acción contenciosa y la acción convencional a través de las fronteras del orden político" (272). En particular, destaca la creciente relevancia que tienen la acción judicial y el recurso a los tribunales en la defensa de derechos:

"Mi inclusión de los abogados... en la política contenciosa puede sorprender a algunos estudiantes de los movimientos sociales. Después de todo, ellos no despliegan las tradicionales actividades disruptivas que los movimientos típicamente usan; no crean organizaciones de movimiento social sostenidas; y encuadran sus demandas en torno a valores tradicionales de la cultura política estadounidense, tales como los derechos civiles. Pero, si estamos interesados en el más amplio rango de política contenciosa, y no simplemente en los movimientos sociales, veremos que estos ejemplos proveen evidencia de que la contención contra la expansión estatal todavía está viva" (272).

Distintos autores han resaltado la importancia de los cortes y de la acción judicial como vehículos de demandas ambientales en contextos tan diversos como Canadá (Harrison, 1996), Estados Unidos (Barnett, 1994) o Brasil (McAllister, 2008). En un giro quizá sorprendente, Dalton y sus colegas (Dalton, Recchia y Rohrschneider, 2003: 752-53) contraponen la protesta $y$ la acción judicial a la "política convencional", considerando a ambas como "prácticas confrontativas" y "actividades no convencionales". Esta forma de entender la acción judicial, próxi- 
ma a lo que aquí llamo litigio, contiene la idea básica de acción basada en la contraposición o confrontación de intereses, sólo que por otros medios. En vez de canalizarse mediante los métodos disruptivos propios de la protesta, en el caso del litigio la confrontación de intereses contrapuestos se dirime mediante los procedimientos de la acción judicial.

Quizá lo más llamativo del enfoque que aquí se propone sea la inclusión de la controversia experta como forma de acción contenciosa. Debe tenerse en cuenta, ante todo, que el conocimiento experto es particularmente relevante en las cuestiones ambientales, tal como ha sido extensamente señalado en la literatura. Entre tantos otros, Beck advierte que quienes se introducen en el activismo ambiental se ven obligados a entremezclarse con el mundo del conocimiento experto o científico, razón por la cual protesta y ciencia son dos partes indisolubles del ambientalismo (Beck, 2002; Azuela, 2006). Y esa exigencia no escapa a legisladores, burócratas, jueces y abogados dedicados a lidiar con cuestiones ambientales. Ahora bien, en la medida en que las cuestiones ambientales son fuertemente controversiales, no es de extrañar que los científicos tomen posición y confronten, a través de sus ideas, sus evidencias y sus demostraciones, sobre esas cuestiones, de modo diferente pero a la par que lo hacen actores sociales y estatales. Della Porta y Diani (2006: 28-29) afirman, en este sentido, que la protesta diferencia a los movimientos sociales de otros tipos de redes que también comparten un marco común de referencia y toman posición sobre cuestiones conflictivas, tales como las "comunidades epistémicas". En esa línea, por controversia experta aquí se entiende un modo de contienda que se dirime en términos de ideas y demostraciones científicas pero bajo la misma lógica de confrontación que subyace a la definición de acción contenciosa: la validez de unas ideas choca contra la validez de otras.

En base a las definiciones hasta aquí examinadas, en lo que sigue se discutirá, a la luz de la casuística argentina, cómo los distintos modos de contienda ambiental se vinculan con la actualización de los derechos ambientales. Antes conviene aclarar que los tres "modos" de contienda no son vistos de manera excluyente ni como "tipos ideales" de acción, en el sentido de que podría esperarse que esos modos se manifiesten "en estado puro". Son entendidos, propiamente hablando, como "modos" o dimensiones de la acción ambiental que, en los casos concretos, pueden combinarse de las maneras más diversas y que también pueden confluir con formas de participación institucionalizada.

\section{Litigio judicial}

Puede decirse que el litigio judicial es el modo de acción contenciosa a través del cual más abiertamente se actualizan los derechos ambientales en la medida en que remite inherentemente al derecho constitucional a un ambiente sano y a los derechos procedimentales concomitantes, los cuales dan sustento al litigio ambiental. Al igual que en muchos otros países, jueces y abogados se han vuelto centrales en la actualización de los derechos ambientales en Argentina. En las actas de un simposio de 2003 sobre legislación ambiental en América latina (Di Paola, 2003), jueces participantes señalaban el rol de los tribunales argentinos como "ha- 
cedores y propagadores" (101) del derecho ambiental en el país, mientras que un funcionario de Estados Unidos destacaba que en América Latina "el derecho ambiental juriprusdencial se ha transformado... en una importante fuente de derecho ambiental positivo" (16).

Lo cierto es que, en Argentina, el litigio ambiental ha proliferado a lo largo y ancho de todo el país durante los últimos quince años, tanto en las cortes federales como en las provinciales. Sin duda, el caso que ha tenido, hasta ahora, mayor resonancia pública ha sido el llamado caso Matanza-Riachuelo, originado por una demanda interpuesta por un grupo de residentes supuestamente afectados por la contaminación del río Matanza-Riachuelo que baña la zona sur de la Región Metropolitana de Buenos Aires. ${ }^{5}$

En 2004, un grupo de vecinos presentó ante la Corte Suprema de Justicia de la Nación (CSJN) una demanda judicial (conocida como causa Beatriz Mendoza) contra el gobierno nacional, el gobierno de la provincia de Buenos Aires, el gobierno de la Ciudad de Buenos Aires y más de cuarenta firmas privadas por los daños que, alegaban, causaba la contaminación del río Matanza-Riachuelo. Los demandantes recurrieron a la nueva figura constitucional de la acción colectiva y fundaron su demanda en el derecho al ambiente sano y el derecho a reparación por daño ambiental.

La CSJN dictó su primer fallo en 2006. Ordenó al gobierno nacional, al gobierno provincial, al gobierno de la Ciudad de Buenos Aires y al Consejo Federal de Medio Ambiente que presentaran de modo conjunto un plan para el saneamiento del Matanza-Riachuelo en el plazo de 30 días. Luego del fallo, la CSJN aceptó un pedido presentado por el Defensor del Pueblo de la Nación y un grupo de organizaciones sociales (Fundación Argentina de Recursos Naturales, Centro de Estudios Legales y Sociales, Greenpeace Argentina y Asociación de Vecinos de la Boca) para participar de la causa Beatriz Mendoza como amicus curiae. El pedido estaba fundamentado en el derecho a la acción colectiva introducido por la reforma constitucional de 1994. La interacción entre el Defensor del Pueblo de la Nación y algunas organizaciones sociales se encontraba, de hecho, en el origen de la historia, dado que desde 2002 venían interactuando en la realización de eventos para discutir y difundir informes que condenaban la crítica situación del MatanzaRiachuelo y que reclamaban que las autoridades tomasen medidas inmediatas.

La primera respuesta estatal al fallo de la CSJN fue la creación de la Autoridad de Cuenca Matanza-Riachuelo (Acumar) en noviembre de 2006, compuesta por cuatro representantes del gobierno nacional, dos de la provincia de Buenos Aires y dos de la Ciudad de Buenos Aires, bajo la presidencia permanente del secretario de Ambiente y Desarrollo Sustentable nacional (Ley 26.168/06). ${ }^{6}$

En 2008, la CSJN dictó un segundo fallo haciendo responsables a los tres niveles de gobierno por la remediación y futura prevención de los daños ambientales en la cuenca. Una vez más, les ordenó formular conjuntamente un plan integrado de saneamiento, a través de la recientemente creada Acumar. También encomendó al Juzgado Federal de Quilmes (luego reemplazado por otros dos juzgados) que monitorease el cumplimento de su sentencia. 
Aunque de menor repercusión en los medios porteños, otro caso paradigmático fue la intervención de la CSJN en la llamada causa Dino Salas. En febrero de 2008, mientras el gobierno provincial comenzaba a preparar el Ordenamiento Territorial de los Bosques Nativos (en base a los requerimientos de la ley nacional de bosques nativos aprobada en 2007), la ONG Asociana presentó, en nombre de un grupo de comunidades indígenas del norte de Salta, un pedido al ministerio provincial de ambiente para que revisase los permisos otorgados en 2007 a una empresa privada para deforestar tierras que las comunidades reclamaban como propias. ${ }^{7}$ Un mes después, la coordinadora provincial de política ambiental, a cargo de preparar el Ordenamiento de Bosques Nativos, dictaminó la clausura preventiva y paralización inmediata de las actividades de deforestación en las tierras en disputa. La coordinadora debió renunciar dos meses más tarde, evidenciando que sus superiores no compartían su decisión.

Viendo que el gobernador se rehusaba a responder a sus demandas, las comunidades indígenas pronto decidieron cambiar de táctica. Constituidas en la Mesa de la Tierra y asistidas por Asociana, Fundapaz, otras organizaciones y abogados porteños, en diciembre de 2008 presentaron ante la CSJN un recurso de amparo para que se detuvieran las actividades de deforestación. En menos de quince días la CSJN se declaró competente en el caso, dictaminó la suspensión temporal de todos los permisos de deforestación otorgados en los cuatro departamentos afectados por las tierras en disputa y convocó a todas las partes involucradas a una audiencia para el 18 de febrero de 2009.

Luego de escuchar a todas las partes, el 26 de marzo la CSJN anuló todos los permisos otorgados en 2007 y prohibió las actividades forestales en los cuatro departamentos en los que se ubicaban las tierras en disputa hasta tanto el gobierno provincial y la SAyDS nacional realizaran una evaluación de impacto ambiental que fuese satisfactoria. En sus considerandos, la CSJN contra-argumentó la posición provincial sosteniendo que la nación tenía el poder de limitar la autonomía provincial cuando esa intervención se justificaba en base al principio precautorio establecido por la Ley General del Ambiente de 2002.

En respuesta al fallo de la CSJN, el gobierno provincial decidió respetar las demandas de las comunidades indígenas. En junio de 2009 reglamentó por decreto el Ordenamiento Territorial recientemente aprobado por ley y decidió clasificar las tierras reclamadas por las comunidades indígenas como tierras de conservación media (categoría II) y no de conservación baja (categoría III), como tenía previsto. Además, decretó que ningún permiso de deforestación podría ser aprobado donde hubiese un conflicto pre-existente sobre la propiedad de la tierra, especificando los conflictos existentes al momento.

Los dos casos muestran bien los alcances y las limitaciones que puede tener el litigio ambiental. En ambos, la intervención de la CSJN produjo un cambio importante en la política estatal. En Matanza-Riachuelo, obligó a que las distintas jurisdicciones involucradas comenzasen a interactuar entre ellas, creasen un organismo interjurisdiccional sui generis para el manejo del río y pusiesen en marcha, no sin contratiempos, un plan integrado de saneamiento. Adicionalmente, los tres 
niveles de gobierno, y en especial los gobiernos municipales, debieron desarrollar nuevas capacidades para dar cuenta de los proyectos de Acumar y las exigencias del monitoreo de la justicia federal. En Salta, la intervención de la Corte llevó a que el gobierno provincial atendiese los reclamos de las comunidades indígenas, modificase el ordenamiento del territorio en disputa y cambiase la política de deforestación para ese mismo territorio.

En contraposición, pueden señalarse tres limitaciones comunes, en buena medida, a los dos casos. Una primera limitación tiene que ver con el restringido alcance geográfico del fallo judicial y de las políticas de él derivadas. En el caso MatanzaRiachuelo, los efectos positivos de la intervención judicial sólo abarcan una fracción de la Región Metropolitana de Buenos Aires, siendo que en ésta existen otras cuencas hidrográficas que también padecen graves problemas de contaminación pero en las cuales no es posible encontrar nada ni remotamente parecido a Acumar y sus políticas de saneamiento. De modo similar, el fallo sobre la causa Dino Salas sólo afectó el ordenamiento de cuatro departamentos de la provincia de Salta, mientras que en el resto de los departamentos siguió predominando el criterio productivista (i.e. pro-deforestación) en la categorización de las tierras. Una segunda limitación está vinculada con las contramarchas de las políticas implementadas, las cuales de un modo u otro escapan al control del poder judicial. El saneamiento del Matanza-Riachuelo está en marcha pero lejos todavía de volverse una realidad palpable, lo cual evidencia tanto la complejidad de la tarea en cuestión como las restricciones organizacionales y políticas de Acumar. En Salta, comunidades indígenas y organizaciones ambientalistas vienen denunciando en el último año la violación por parte de empresas y del gobierno provincial de las prohibiciones a la deforestación decretadas para los cuatro departamentos afectados por el fallo de la CSJN. Una tercera dificultad, vinculada íntimamente con la anterior y generalizada a estos y otros casos, tiene que ver con el bajo poder de policía tanto del poder judicial como de las agencias administrativas encargadas de ejecutar las órdenes del primero. Este déficit afecta el poder de aplicación de la ley y lesiona, a la larga, los efectos de los fallos judiciales.

Sin embargo, más allá de esos alcances y limitaciones, ambos casos muestran la apropiación que ciudadanos, organizaciones sociales de diverso tipo y actores judiciales hacen del derecho al ambiente sano y los nuevos recursos legales introducidos a partir de la reforma de 1994. El caso Matanza-Riachuelo fue particularmente relevante porque, amén de instalar el saneamiento del "río más contaminado del país" en la agenda de los tres niveles de gobierno, "demostró" la relevancia de los derechos ambientales y la validez del litigio como instrumentos para vehiculizar reivindicaciones ambientales. La mayoría de los activistas ambientales (profesionales o de base), al igual que muchos funcionarios públicos, reconocen hoy día el impacto de la causa Beatriz Mendoza tanto en la amplificación pública de los derechos ambientales como en la política ambiental. Todo ello sirve, junto con la repercusión de otros casos como la causa Dino Salas, como antecedente para organizaciones y ciudadanos que deciden recurrir al litigio judicial como alternativa a, o complemento de, otros modos de acción. 


\section{Protesta ambiental}

En Argentina, la protesta ambiental y las formas vinculadas de organización y movilización social han crecido notoriamente durante los últimos quince años, centrándose en casos de explotación de recursos naturales en gran escala. Las protestas contra la minería a cielo abierto han proliferado en las provincias orientales y patagónicas. El primer hito de esas protestas fue la lucha de la Asamblea de Vecinos Autoconvocados de Esquel contra la explotación de oro en esa localidad, ubicada en la provincia patagónica de Chubut. Fue la primera vez que demandas sociales expresadas de modo contencioso por una organización de base cambiaron el rumbo de una política ambiental (la prohibición mediante ley provincial de la actividad minera metalífera en la modalidad a cielo abierto y la utilización de cianuro en todo el territorio provincial), dejando un legado tanto para futuras movilizaciones sociales como para empresas y organizaciones estatales (Reboratti, 2007, 2008; Svampa, Solá Álvarez y Bottaro, 2009).

Tras el suceso de la protesta de Esquel, surgirían en distintos puntos del país asambleas de vecinos, asambleas ciudadanas o figuras similares para posicionarse contra la minería a cielo abierto, el uso del glifosato u otros problemas. Esas organizaciones incluso llegarían a formar redes entre sí. ${ }^{8}$ Pero un caso se destacaría de todos los demás por su alto impacto en la política nacional: el conflicto por las pasteras del río Uruguay, iniciado en 2004-2005 en la ciudad entrerriana de Gualeguaychú. ${ }^{9}$

Más que cualquier otro caso, la protesta contra las dos pasteras que se proyectaba construir en la costa uruguaya del río Uruguay ${ }^{10}$ elevó la posición de las cuestiones ambientales en la agenda pública nacional, al punto que forzó un cambio en la política externa ambiental del presidente Néstor Kirchner. Algunos analistas incluso consideran que esa protesta devino un parte-aguas en la actualización del derecho al ambiente sano. Tal es el caso de Merlinsky (2009: 128), quien afirma que

"El conflicto por las plantas de celulosa en el Río Uruguay representa un momento fundacional en referencia a la legitimación del derecho al ambiente sano como derecho constitucional de incidencia colectiva".

Merlinsky (2009) incluso va más lejos al sostener que la sentencia de la CSJN en el caso Matanza-Riachuelo fue posible por su "retroalimentación" de la protesta contra las pasteras. Svampa y Antonelli (2009: 20) reconocen el impacto que tuvo el caso de las pasteras en la fijación de agenda pero no parecen aceptar que éste haya tenido un efecto positivo en la legitimización de los reclamos ambientales en general:

"La experiencia que tuvo el mérito de colocar en la agenda pública la nueva cuestión socioambiental, a nivel nacional, fue Gualeguaychú, entre 2005 y $2006 \ldots$ [Sin embargo,] por paradójico que pueda parecer, la instalación de la agenda socioambiental, capitalizada políticamente por el gobierno de los Kirchner, lejos estuvo de servir a la apertura de la discusión de otras causas socioambientales; antes bien, sirvió para el ocultamiento y la denegación de otros conflictos que ya comenzaban a recorrer diferentes provincias argentinas, a raíz de la introducción del modelo minero" (corchetes míos). 
Cualquiera sea la interpretación que se haga de sus alcances, es innegable que el caso de las pasteras del río Uruguay alcanzó mayor resonancia pública nacional que cualquier otro, ocupando la tapa de los principales diarios porteños durante varias semanas. Aunque los protestantes recurrieron (sin éxito) al litigio judicial en fueros nacionales e internacionales, la clave de la resonancia pública del caso estuvo en la persistencia y la radicalización de la protesta (centrada en el bloqueo de un puente internacional con un estilo netamente "piquetero") y en su constante presión para que el gobierno nacional tomase un curso de acción contra Uruguay.

Dos características son comunes a las protestas ambientales que se sucedieron a lo largo y ancho del país durante los últimos quince años. En primer lugar, el recurso a los derechos ambientales: el derecho al ambiente sano y el aparato legal a él asociado se han convertido en marco de referencia y en herramientas que viejas y nuevas organizaciones ambientales utilizaron para construir y expresar sus reivindicaciones. Por esa vía, las organizaciones ambientales otorgaron a los derechos ambientales una vigencia y legitimidad que parecían estar adormecidas antes de las primeras protestas que tuvieron lugar en los inicios del nuevo siglo. En segundo lugar, el impacto en las políticas públicas: de distintas maneras y en distintos grados, numerosas protestas ambientales han afectado las políticas de los tres niveles de gobierno, tanto en el plano legislativo (Bonasso, 2011; Rey, 2011; Christel, 2012) como en el plano burocrático-administrativo (Gutiérrez e Isuani, 2014). Ciertamente, no todas las protestas alcanzaron sus objetivos ni tuvieron un impacto directo en las políticas públicas, y sería exagerado afirmar que la proliferación de protestas y litigios ambientales cambió sustancialmente el rumbo de la política ambiental del país o hizo mella en las actividades económicas disputadas. Pero existen numerosas evidencias de que gobiernos de los tres niveles se vieron obligados a prestar más atención a las demandas y posiciones de las organizaciones ambientales, respondiendo en algunos casos con la sanción de nuevas leyes, con la reorganización de las dependencias ambientales y/o con la sustitución de funcionarios. Más allá del impacto en las políticas públicas concretas, es innegable que durante la década, y en buena medida como resultado de la contienda ambiental (bajo los dos modos hasta aquí analizados: litigio y protesta), se ha desarrollado en Argentina una policy culture en torno a la cuestión ambiental, esto es, "un interés público amplio y duradero en una cuestión en particular en una sociedad dada" (Steinberg, 2001: 153-54). Ese interés incluye una expectativa general de que el gobierno tiene que ocuparse de la cuestión en juego. No implica la existencia de un consenso entre todos los interesados. Implica que todos consideran, desde sus respectivas visiones, que la cuestión merece ser objeto de política pública, que el Estado le dedica recursos legales, organizacionales y financieros, que organizaciones sociales de las más diversas evalúan que la cuestión amerita movilizarse e ir al encuentro del Estado y que los medios de comunicación masiva deciden que vale la pena cubrir extensamente el tema. 


\section{Controversia experta}

De los tres, éste es sin dudas el modo menos asible de contienda ambiental y también el más ubicuo. Dos aspectos deben ser distinguidos: el debate entre expertos y el uso del discurso científico en contiendas sociales y judiciales.

El primer aspecto de las controversias expertas es el más silencioso, el menos notorio y, por eso mismo, el menos estudiado en Argentina: los debates entre expertos sobre qué constituye (un nivel aceptable de) contaminación y degradación ambientales (o qué riesgos ambientales merecen ser atendidos) y cuáles son sus causas y mejores soluciones. Quizá el caso más difundido sea el debate en torno al uso de glifosato en la producción de soja, especialmente a partir de que Andrés Carrasco, investigador del CONICET con sede en el Laboratorio de Embriología Molecular de la UBA, publicó en 2010 un artículo alertando sobre los efectos nocivos del glifosato en el desarrollo de embriones de vertebrados (Paganelli et al., 2010), el cual fue bastante divulgado por los medios de comunicación y contestado por otros expertos. De tiempo en tiempo, debates sobre el impacto ambiental de agroquímicos usados en la producción de soja (y también sobre la cuestión vinculada de la expansión de la frontera agrícola) irrumpen la atención de los medios. Pero el debate pronto se desvanece de la agenda pública.

Esto no significa que las investigaciones científicas y los debates expertos sean inexistentes, como la polémica desatada a partir del artículo de Carrasco todavía hoy lo atestigua. ${ }^{11}$ Lo que está en juego aquí es la poca diseminación pública de hallazgos científicos y debates expertos. El problema es señalado de modo polémico por Antonio Braislovsky, economista e historiador ambiental, de la siguiente manera:

"Nosotros tenemos un sistema científico que penaliza la difusión. A la gente del CONICET y a la de las universidades les restan puntos si hacen notas periodísticas, si aparecen en los medios. Está muy mal visto en nuestro sistema científico hablar con el gran público, porque se supone que se pierde jerarquía científica" (Ventura, 2010: 9).

Juan José Cantero, ex secretario de Promoción Científica de la provincia de Córdoba, lo pone en estos términos:

"La Argentina, en el caso de los investigadores individuales, no está mal posicionada según los indicadores de ciencia y tecnología en la escala latinoamericana. Ahora... aparecen unos cuantos déficits en lo que yo veo que es la transferencia de conocimiento a los que debieran apropiarse de él... hay un abismo entre la sociedad y la producción de conocimiento... El sistema científico argentino tiene una característica muy particular en el reconocimiento del mérito, que usa la medición bibliométrica como una cuestión casi sine qua non para evaluar al investigador. Y está bien, no es discutible, porque es una forma práctica y mucho más fácil que algunos otros indicadores difíciles de constatar. Pero hay otras mediciones de prestigio en la Argentina que lamentablemente están muy incompletas, como la medición de transferencia que hacen los investigadores... hablo de transferencias comunes, a la gente común, a municipalidades, ONGs, comunas y organismos públicos... El mérito está asociado a la cuestión bibliométrica casi en forma ex- 
cluyente, y es un déficit del sistema no incluir dentro de los méritos la cuestión de la transferencia, la divulgación y la difusión" (Moledo, 2010: 19).

Podríamos agregar numerosos testimonios y evidencias que refuerzan la poca diseminación pública de los hallazgos científicos y los debates expertos en torno a la protección y la contaminación ambientales. Sin embargo, desde 2002 ha sido sancionada una abundante legislación ambiental; y debemos presumir que opiniones y debates expertos han moldeado las decisiones ejecutivas y parlamentarias que estuvieron detrás de esa legislación. Lo relevante, desde el punto de vista de este trabajo, es que esa legislación es la que define nada menos que los "presupuestos mínimos" de protección ambiental, es decir, es la que traduce el derecho al ambiente sano a criterios (más o menos) tangibles, tales como las categorías para clasificar los bosques nativos y determinar las exigencias de conservación de los mismos.

Pero, dado que esos debates, cuando existen, raramente alcanzan estado público, es difícil evaluar su contribución en la redefinición y aplicación de los derechos ambientales. Es por eso que el análisis de su impacto normativo y social todavía está fuertemente mediado por el uso que actores judiciales y activistas sociales (y sus oponentes) hacen de la información experta. Más allá de eso, el uso y la productividad social del conocimiento científico tiende a permanecer, en Argentina, dentro del ámbito de, parafraseando a Bobbio (1986), el "poder invisible".

El segundo aspecto, el uso del discurso científico en las demandas sociales y en las sentencias y actos judiciales es, por todo lo dicho, el más notorio. En casos como las protestas contra las pasteras o la megaminería, los activistas se oponen a los proyectos y obras en danza objetando la "parcialidad" de los datos y estudios técnicos provistos por empresas y funcionarios públicos sobre la base de conocimiento experto "alternativo", combinado con otras consideraciones tales como los derechos humanos, el desarrollo regional o las identidades locales.

Como remarca Azuela (2006), la discusión pública de cuestiones naturales es comúnmente realizada dentro de los marcos conceptuales del discurso científico, lo que ayuda a legitimar los reclamos ambientales como intereses generales, no sesgados. Tanto los expertos como los activistas que recurren a enunciados científicos rechazan la idea de que la naturaleza es alguna entidad socialmente construida. Es por esta razón que, como vimos más arriba, protesta y ciencia son, para Beck, Azuela y tantos otros, componentes inseparables del campo ambiental.

Svampa, Solá Álvarez y Bottaro (2009: 126-28) resaltan cómo la articulación entre el conocimiento experto "independiente" y la movilización ambiental condujo al éxito de la protesta de Esquel de 2003 contra la instalación de una mina de oro, transformando la protesta en un caso líder para las subsecuentes movilizaciones anti-mineras. De modo similar, el conocimiento experto y la validez de información científica alternativa han estado en el núcleo del caso de las pasteras del río Uruguay. Estos y muchos otros ejemplos muestran cuán central es el uso del conocimiento experto para todas las partes involucradas en una protesta ambiental. 
De manera semejante, los abogados y jueces involucrados en litigios ambientales fundamentan sus pareceres y sentencias en informes expertos, algunas veces especialmente requeridos para el caso en cuestión. La dependencia de las decisiones judiciales respecto del conocimiento experto es vívidamente expresada por un funcionario del Departamento de Justicia de los Estados Unidos en un simposio sobre legislación ambiental en América latina realizado en 2003 en Buenos Aires:

"Nuestro rol en este contexto... es el de educar a la corte de manera tal que pueda decidir con toda la información necesaria al imponer condenas y compensaciones... Las causas ambientales son por lo general mucho más complicadas que las típicas acciones penales o causas por agravios... A menudo se centran en cuestiones altamente técnicas, tales como el pautado de emisiones de aire o los humos contaminantes, y a menudo se vuelven en contra de la evidencia de un experto sobre las actividades del acusado y sobre las consecuencias de dichas actividades. Esto requiere que expliquemos la ciencia que apoya la prueba para poder persuadir a la persona que evalúa los hechos, quien por lo general no tiene un doctorado en química o biología, que debería fallar a nuestro favor. Este proceso de educación científica es importante no sólo para el establecimiento de infracciones en causas ambientales, sino también para idear las reparaciones apropiadas" (Di Paola, 2003: 200-201).

Sin embargo, si las decisiones judiciales parecen depender de las evidencias científicas de la manera señalada, lo contrario también es cierto. Las evidencias científicas sobre contaminación y degradación ambiental no son conclusivas y su contribución en la toma de decisiones es, en última instancia, política. No depende exclusivamente de los científicos decidir qué evidencias deben ser tomadas como válidas sino también de los jueces que, al decir de Austin, crean realidad con sus sentencias y, con anterioridad a ellos, de los legisladores y funcionarios que fijan los principios y estándares de protección ambiental.

Así, los contendientes sociales y sus oponentes, al igual que los actores judiciales, sistemáticamente respaldan su derecho a un ambiente sano con fundamentos y evidencias científicas de los daños o riesgos en cuestión. Además de eso, el conocimiento científico permea la regulación legislativa y los procedimientos y medidas administrativas relacionados con el uso de recursos naturales y la protección ambiental. Así visto, el uso del conocimiento experto puede ser simplemente considerado como una dimensión del litigio y de la protesta. Con todo, la razón por la cual prefiero considerar la controversia experta como un modo separado de contienda ambiental es porque la fuente de esas controversias reside fuera del campo ambiental y del campo legal. Mediante el estudio de los litigios y protestas ambientales podemos aprender mucho sobre el uso social del conocimiento experto pero todavía sabremos poco acerca de la producción de conocimiento y la manera en que los expertos se vinculan con los derechos y las contiendas ambientales. Cómo los expertos discuten entre sí, cómo interactúan con los actores políticos y económicos y cómo se vinculan con las organizaciones sociales son preguntas de investigación que vale la pena investigar por sí mismas. 


\section{Consideraciones finales}

A lo largo de este trabajo, se destaca la relevancia que ha adquirido la contienda ambiental, en sus distintos modos, en la apropiación y actualización de los derechos ambientales en Argentina. Se muestra, a partir de algunos casos paradigmáticos, cómo la contienda ambiental ha operado como un canal para la puesta en vigencia y legitimación de derechos ambientales que habían sido introducidos con la reforma constitucional de 1994 pero que prácticamente habían permanecido adormecidos hasta inicios del nuevo siglo. Lo cierto es que casi nadie prestó mucha atención al derecho a un ambiente sano y a los derechos procedimentales concomitantes antes de que las contiendas en torno a la mina de oro en Esquel, las pasteras del río Uruguay y la contaminación del río Matanza-Riachuelo, junto con otros casos, los pusieran en primer plano. Concomitantemente, se argumenta que esos y otros casos de contienda ambiental contribuyeron a posicionar las cuestiones y derechos ambientales en la agenda pública gracias a la amplia cobertura mediática y la respuesta estatal que tuvieron las protestas sociales, los litigios judiciales e incluso algunas controversias expertas vinculados con la cuestión ambiental. Ese posicionamiento se aprecia con sólo rastrear la evolución de la cobertura de las noticias ambientales en los medios gráficos y electrónicos. Finalmente, se sostiene que la contienda ambiental ha impactado las políticas públicas referidas al ambiente, tanto en el plano normativo como en el burocrático. Como se ha advertido, eso no quiere decir que la contienda ambiental haya cambiado sustancialmente el rumbo de las políticas ambientales o la regulación de las actividades económicas. Pero es innegable que las cuestiones ambientales han ingresado crecientemente en la agenda institucional de los tres niveles de gobierno y que éstos se han visto obligados a responder a las demandas ambientales con innovaciones normativas y burocráticas.

En contraste con estos hallazgos, debe notarse que las innovaciones normativas y burocráticas referidas, amén de sus problemas de aplicación y efectividad, raramente incluyen mecanismos significativos para la participación institucionalizada en la formulación y ejecución de políticas públicas. En este aspecto, cabe remarcar que los derechos procedimentales consagrados en la constitución reformada no incluyen ninguna provisión explícita para la promoción de ese tipo de participación. De hecho, esos derechos, más que promover la participación institucionalizada en la formulación de políticas públicas, han favorecido el litigio judicial y la protesta social.

Vinculado con esta escasez de canales para la participación institucionalizada en la formulación e implementación de políticas ambientales, podría concluirse que la contienda ambiental ha sido más expeditiva o más efectiva en la fijación de agenda y en la definición del problema que en la solución de este último y en la formulación de una política ambiental propiamente hablando. A ello puede agregarse la hipótesis según la cual el impacto último de las contiendas ambientales en las políticas públicas dependerá, entre otras cosas, tanto de cómo se combinen los distintos modos de contienda como de su articulación con mecanismos de participación institucionalizada. 
Para poner a prueba estas últimas conclusiones, es necesario profundizar las investigaciones sobre la relación entre participación social y políticas ambientales persiguiendo un enfoque más amplio de las distintas formas de acción y participación que inciden en la definición pública de las cuestiones ambientales, en la actualización de los derechos ambientales y en la formulación e implementación de políticas públicas. Para ello se propone, en primer lugar, estudiar en mayor profundidad cómo los modos de contienda ambiental se combinan entre sí y se conjugan con instancias de participación institucionalizada en los casos concretos. Aquí se trató a los tres modos de contienda ambiental separadamente por razones analíticas, esto es, para entender mejor en qué consiste y cómo opera cada uno de ellos. Pero, como ya se advirtió, cada uno de esos modos no se da en estado puro sino en combinación con otros modos de acción contenciosa y/o institucionalizada.

En particular, se recomienda, en segundo lugar, prestar más atención al estudio de las controversias expertas y su vinculación con las otras formas de acción y con las políticas públicas. Como lo atestiguan las publicaciones y tesis citadas en este texto (y tantas otras), los estudios sobre las distintas formas de participación y sobre políticas públicas vinculadas con la cuestión ambiental han venido creciendo durante los últimos años. Pero todavía sabemos muy poco sobre cuáles son los términos de las controversias expertas en la materia, cómo se vinculan con la legislación y con las políticas estatales y cómo interactúan con los otros modos de participación ambiental (contenciosa o institucionalizada).

En tercer lugar, por participación institucionalizada no debería entenderse solamente las "nuevas formas de gestión pública" o las "instituciones participativas" referidas en el apartado sobre el tema. Tanto los enfoques centrados en estas formas de participación como aquellos centrados en la acción contenciosa suelen perder de vista las formas clásicas de participación política como la contienda electoral y la arena parlamentaria. Sin embargo, algunos de los estudios citados en este trabajo sugieren que debemos prestar más atención a cómo estas formas clásicas de participación interactúan con la acción contenciosa y la participación institucionalizada en la formulación e implementación de políticas públicas. Finalmente, se propone no perder de vista la perspectiva comparativa en dos sentidos diferentes. Por un lado, el carácter "emergente" de los derechos constitucionales no parece ser privativo del área ambiental como tampoco son exclusivas de esa área las formas de contienda aquí examinadas. Por lo tanto, una comparación entre distintas áreas de política pública podría arrojar más luz sobre la relación entre participación social (ampliamente entendida) y apropiación y realización de derechos. Por otro lado, pese a sus particularidades, el caso argentino no parece distanciarse radicalmente de otros países federales como Brasil, Canadá y Estados Unidos. En todo caso, mediante una perspectiva comparada podrá echarse más luz sobre el caso argentino y al mismo aportar conclusiones más generalizables. 


\section{Referencias}

1. Versiones preliminares de este trabajo fueron presentadas en el panel "Conflictos, derechos y cuestión ambiental en América Latina" del Congreso 2010 de LASA, el panel "Water Politics in Latin America", del Congreso 2012 de LASA y las Primeras Jornadas de Investigación en Política y Gobierno de la UNSAM (2014), así como en el seminario permanente del Grupo Ambiente y Política de la Escuela de Política y Gobierno de la UNSAM (2012). Quiero agradecer a todos los participantes de esas reuniones por sus valiosos comentarios y críticas, en particular a Patrice Melé, Gabriela Merlinsky, Marisa von Bülow, Jessica Buds, Rebecca Abers, Margaret Keck, Gabriela Delamata, Catalina Smulovitz, Lucas Christel y Patricio Besana. Como es de rigor, todas las falencias de este trabajo corren por mi exclusiva cuenta.

2. A lo largo del texto, y a efectos de simplificación, los términos acción contenciosa y contienda serán utilizados indistintamente como términos sinónimos.

3. Todas las traducciones a lo largo del texto son mías.

4. $<$ http://www.unece.org/env/pp/welcome.html> última visita: 17 febrero 2014.

5. Para un detallado examen del caso Matanza-Riachuelo, cf. Merlinsky $(2009,2013)$.

6. Mediante el Decreto 2.103/13, en diciembre de 2013 el gobierno nacional modificó está última disposición otorgando al presidente de Acumar el rango de Secretario de Estado y determinando que el mismo será nombrado por decreto del Poder Ejecutivo Nacional, desvinculándolo de ese modo de la Secretaría de Ambiente y Desarrollo Sustentable.

7. Para un análisis de la causa Dino Salas y su impacto en la política provincial de bosques nativos, cf. Luft (2013), de donde se extraen los detalles aquí consignados.

8. Sobre las resistencias a la minería a lo largo del país y su impacto en las políticas provinciales del sector, cf. Svampa, Sola Álvarez y Bottaro (2009); Christel (2012); Delamata (2013).

9. Para un análisis de este caso y su impacto en la política ambiental, cf. Palermo y Reboratti (2007); Alcañiz y Gutiérrez (2009); Merlinsky (2009); Delamata (2009); Bueno (2010); Gutiérrez y Almeira (2011).

10. Finalmente, uno de los proyectos (de la empresa española ENCE) fue retirado por la propia empresa mientras que el otro (Botnia/UPM) fue consumado y la planta está actualmente en pleno funcionamiento.

11. Esta polémica se ve acompañada por un número creciente de litigios judiciales y protestas sociales contra el uso del glifosato y otros agroquímicos, especialmente en las provincias de Córdoba, Santa Fe y Entre Ríos.

\section{Bibliografía}

H. ACSELRAD (2006), "Las políticas ambientales ante las coacciones de la globalización", en H. ALIMONDA(comp.), Los tormentos de la materia: aportes para una ecología política latinoamericana, Buenos Aires, CLACSO.

G. ACUÑA (2003), "El principio de acceso a la información, participación y justicia en materia ambiental en América Latina: ¿nuevos espacios, nuevos derechos?”, en M. E. DI PAOLA (comp.), Simposio de jueces y fiscales de América Latina: aplicación y cumplimiento de la normativa ambiental, Buenos Aires, FARN.

I. ALCAÑIZ y R. A. GUTIÉRREZ (2009), "From Local Protests to the International Court of Justice: Forging Environmental Foreign Policy in Argentina", en P. G. HARRIS (comp.), Environmental Change and Foreign Policy, New York, Routledge Press.

H. ALIMONDA (2003), Ecología politica, naturaleza, sociedad y utopía, Buenos Aires, CLACSOASDI-FAPERJ.

H. ALIMONDA (2006), Los tormentos de la materia: aportes para una ecología política latinoamericana, Buenos Aires, CLACSO.

G. ALVARADO MERINO et al. (2008), Gestión ambiental y conflicto social en América Latina, Buenos Aires, CLACSO.

L. AVRITZER (2002), Democracy and the Public Space, Oxfordshire, Princeton University Press. 
L. AVRITZER (2009), Participatory Institutions in Democratic Brazil, Washington, Woodrow Wilson Center Press.

A. AZUELA (2006), Visionarios y pragmáticos: una aproximación sociológica al derecho ambiental, México, UNAM/Fontamara.

H. C. BARNETT (1994), Toxic Debts and the Superfund Dilemma, Chapel Hill and London, The University of North Carolina Press.

U. BECK (2002), Ecological Politics in an Age of Risk, Cambridge, Polity Press.

N. BOBBIO (1986), El futuro de la democracia, México, Fondo de Cultura Económica.

M. BONASSO (2011), El Mal. El modelo K y la Barrick Gold: amos y servidores en el saqueo de la Argentina, Buenos Aires, Planeta.

M. P. BUENO (2010), "Política exterior y medio ambiente en la Argentina. La influencia de los actores subnacionales y no estatales en la toma de decisiones entre 1989 y 2009", Tesis de Doctorado, Facultad de Ciencia Política y Relaciones Internacionales, Universidad Nacional de Rosario.

L. G. CHRISTEL (2012), "Incidencia de las resistencias sociales en las legislaciones provinciales. Los casos de Córdoba y Catamarca (2003-2008)”, Tesis de Maestría, Escuela de Política y Gobierno, Universidad Nacional de San Martín.

R. J. DALTON, S. RECCHIA y R. ROHRSCHNEIDER (2003), "The Environmental Movement and Modes of Political Action", Comparative Political Studies, Vol. 36, No 7.

G. DELAMATA (2009), “LLa ciudadanía poblana? El movimiento asambleario de Gualeguaychú: la construcción y el reclamo de un derecho colectivo", en G. DELAMATA (comp.), Movilizaciones sociales: ¿nuevas ciudadanías? Reclamos, derechos, estado en Argentina, Bolivia y Brasil, Buenos Aires, Biblos.

G. DELAMATA (2013), “Actualizando el derecho al ambiente: movilización social, activismo legal y derecho constitucional al ambiente de "sustentabilidad fuerte" en el sector extractivista megaminero", Entramados y Perspectivas, Vol. 3, No 3 .

D. DELLA PORTA y M. DIANI (2006), Social Movements: An Introduction, Oxford, Blackwell.

M. E. DI PAOLA (2003), Simposio de jueces y fiscales de América Latina: aplicación y cumplimiento de la normativa ambiental, Buenos Aires, FARN.

A. DOWNS (1972), "Up and Down with Ecology - The 'Issue-Attention Cycle", Public Interest, $\mathrm{N}^{\circ} 28$.

R. A. GUTIÉRREZ y G. ALMEIRA (2011), "Global Production, Local Protest, and Environmental Foreign Policy: Argentina and the Uruguay River Pulp Mill Projects", en J. HEINE y R. THAKUR (comp.), The Dark Side of Globalization, Tokio, United Nations University Press.

R. A. GUTIÉRREZ y F. J. ISUANI (2014), "La emergencia del ambientalismo estatal y social en Argentina”, Revista de Administração Pública, Vol. 48, № 2.

M. A. HAJER (1995), The Politics of Environmental Discourse: Ecological Modernization and the Policy Process, Oxford, Oxford University Press.

J. HANNIGAN (2006), Environmental Sociology, London and New York, Routledge.

K. HARRISON (1996), Passing the Buck: Federalism and Canadian Environmental Policy, Vancouver, University of British Columbia Press.

R. P. HISKES (2009), The Human Right to a Green Future, Cambridge, Cambridge University Press. E. P. JIMÉNEZ (2003), "Sistema constitucional argentino y distribución de competencias ambientales", en M. E. DI PAOLA (comp.), Simposio de jueces y fiscales de América Latina: aplicación y cumplimiento de la normativa ambiental, Buenos Aires, FARN.

J. LUFT (2013), "Moving Floors: The Obstacles to Guaranteeing Environmental Protection of Native Forests in the Context of Argentina's Federalism”, Tesis de Maestría, Escuela de Política y Gobierno, Universidad Nacional de San Martín.

A. MCADAM, S. TARROW y C. TILLY (2001), Dynamics of Contention, Cambridge and New York, Cambridge University Press.

L. K. MCALLISTER (2008), Making Law Matter: Environmental Protection and Legal Institutions in Brazil, Stanford, Stanford University Press.

G. MERLINSKY (2009), “Atravesando el río: la construcción social y política de la cuestión ambiental 
en Argentina. Dos estudios de caso en torno al conflicto por las plantas de celulosa en el río Uruguay y al conflicto por el saneamiento de la cuenca Matanza-Riachuelo", Tesis de Doctorado, Universidad de Buenos Aires/Universidad París VIII.

G. MERLINSKY (2013), Politica, derechos y justicia ambiental: el conflicto del Riachuelo, Buenos Aires, Fondo de Cultura Económica.

L. MOLEDO (2010), “Ciencia y sociedad: un desencuentro", Página 12, 18 Agosto 2010.

G. NAVARRA (2010), “Divino Tesoro”, Revista La Nación, 19 Septiembre 2010.

C. OFFE (1992), Partidos politicos y nuevos movimientos sociales, Madrid, Editorial Sistema.

A. PAGANELLI et al. (2010), "Glyphosate-Based Herbicides Produce Teratogenic Effects on Vertebrates by Impairing Retinoic Acid Signaling”, Chemical Research in Toxicology, Vol. 23, № 10. V. PALERMO y C. REBORATTI (2007), Del otro lado del río: ambientalismo y política entre uruguayos y argentinos, Buenos Aires, Edhasa.

E. PERUZZOTTI y C. SMULOVITZ (2002), “Accountability social: la otra cara del control”, en E. PERUZZOTTI y C. SMULOVITZ (comps.), Controlando la política: ciudadanos y medios en las nuevas democracias latinoamericanas, Buenos Aires, Temas.

C. REBORATTI (2007), “Ambientalismo y conflicto ambiental en el Río Uruguay”, en V. PALERMO y C. REBORATTI (comps.), Del otro lado del río: ambientalismo y política entre uruguayos y argentinos, Buenos Aires, Edhasa.

C. REBORATTI (2008), "Environmental Conflicts and Environmental Justice in Argentina", en D. V. CARRUTHERS (comp.), Environmental Justice in Latin America: Problems, Promise, and Practice, Cambridge and London, The MIT Press.

M. REY (2011), "Federalismo y políticas públicas en Argentina: articulación nación-provincia en los consejos federales", Tesis de Doctorado, Escuela de Política y Gobierno, Universidad Nacional de San Martín.

D. A. SABSAY (2003), “Constitución y medio ambiente en el marco del desarrollo sustentable”, en M.

E. DI PAOLA (comp.), Simposio de jueces y fiscales de América Latina: aplicación y cumplimiento de la normativa ambiental, Buenos Aires, FARN.

P. STEINBERG (2001), Environmental Leadership in Developing Countries: Transnational Relations and Biodiversity Policy in Costa Rica and Bolivia, Cambridge and London, The MIT Press.

M. SVAMPA y M. A. ANTONELLI (2009), "Introducción: hacia una discusión sobre la megaminería a cielo abierto", en M. SVAMPA y M. A. ANTONELLI (comps.), Minería transnacional, narrativas del desarrollo y resistencias sociales, Buenos Aires, Biblos.

M. SVAMPA, M. SOLÁ ÁLVAREZ y L. BOTTARO (2009), "Los movimientos contra la minería metalífera a cielo abierto: escenarios y conflictos: entre el 'efecto Esquel' y el 'efecto La Alumbrera", en M. SVAMPA y M. A. ANTONELLI (comps.), Minería transnacional, narrativas del desarrollo y resistencias sociales, Buenos Aires, Biblos.

S. TARROW (2011), Power in Movement: Social Movements and Contentious Politics, Cambridge, Cambridge University Press.

C. TILLY (1986), The Contentious French, Cambridge and London, The Belknap Press of Harvard University Press.

C. TILLY (2008), Contentious Performances, Cambridge, Cambridge University Press.

C. TILLY y L. J. WOOD (2010), Los movimientos sociales, 1768 - 2008: desde sus orígenes a Facebook, Barcelona, Crítica.

A. VENTURA (2010), "En la Argentina, la difusión científica está penalizada", La Nación, 21 julio 2010

Recibido: 06/05/2014. Aceptado: 23/02/2015.

Ricardo A. Gutiérrez, "Teoría y praxis de los derechos ambientales en Argentina". Revista Temas y Debates. ISSN 1666-0714, año 19, número 30, julio-diciembre 2015, pp. 13-36. 